\title{
Application of Health Education Combined with Psychological Nursing on Patients Receiving Cardiothoracic Surgery
}

\author{
Qin Shen, Chuanxiu Wang* \\ Department of Cardiothoracic Vascular Surgery, Renmin Hospital, Hubei University of Medicine, Shiyan, \\ Hubei, China,442000
}

Address: Chaoyang District Road No. 39, Shiyan City, Hubei Prov, P.R. China,442000

*Corresponding author: Chuanxiu Wang, E-mail: hubeiwenbo@163.com

Keywords: health education; psychological nursing; cardiothoracic surgery; effect

\begin{abstract}
To analyze the application effect of health education combined with psychological nursing on the patients receiving cardiothoracic surgery, 70 patients receiving cardiothoracic surgery in out hospital from June 2016 to January 2018 were chosen as the objects of study. They were classified into two groups at random according to the numeration table. The conventional nursing was conducted for the control group (35 cases), while health education combined with psychological nursing was applied in the research group (35 cases). Clinical nursing effects of both groups were summarized and compared. Result show that, Visual analogue scale (VAS) scores of the research group after receiving nursing for $2 \mathrm{w}$ and $4 \mathrm{w}$ were significantly lower than that of control group, and the differences had statistical significance $(\mathrm{P}<0.05)$. The compliance rate of research group was significantly higher than that of control group, and the differences had statistical significance $(\mathrm{P}<0.05)$. Therefore, the application of health education combined with psychological nursing for the patients receiving cardiothoracic surgery contributes to relieving patients' pain score and improving their clinical compliance, so it deserves to be promoted and applied clinically.
\end{abstract}

As modern medical treatment makes progress in medical model of psychological and social sector, the influence of psychological factors and social factors on disease prognosis, curative effect and treatment security receives more and more attention. As everyone knows, surgery as a strong stress source may easily give rise to patients' strong and prominent psychological and physiological response. Even, psychological and vital signs change. This is averse to the development of clinical care and nursing content [1-3]. The effect of nursing intervention in the treatment period of cardiothoracic surgery has been verified, but the specific nursing content has not been unified. 70 patients receiving cardiothoracic surgery in the hospital from June 2016 to January 2018 were chosen as the objects of study to analyze the application effect of health education combined with psychological nursing on the patients receiving cardiothoracic surgery so as to provide the reference for clinical treatment.

\section{DATA AND METHOD}

\subsection{General data}

70 patients receiving cardiothoracic surgery in out hospital from June 2016 to January 2018 were chosen as the objects of study. All of them received relevant examinations which showed they had received cardiothoracic surgery. Those with diabetes, hypertension or other organ function obstacle were rejected. There were 46 male patients and 24 female patients. The age ranged from 26 to 80 , and the average age was $56.13 \pm 1.25$. There were 25 cases with closed drainage of thoracic cavity, 27 cases with spontaneous pneumothorax and 18 cases with coronary heart disease. They were classified into control group (35 cases) and research group (35 cases) at random according to the numeration table. The differences in baseline information of both groups had no statistical significance $(\mathrm{P}>0.05)$. 


\subsection{Method}

1) Conventional nursing was conducted for the control group, including disease observation, basic psychological counseling and life nursing, etc.

2) On the basis of control group, health education and psychological nursing were added for the research group: (1)health education: before the surgery, the responsible nursing staff should enhance communication with the patients, know their illness degree, therapeutic scheme and basic information, complete pre-surgical evaluation and give target health education. The education methods should be diversified. For example, relevant department regulations, diseases knowledge, and health knowledge may be posted. The responsible nursing staff should adopt simple language to popularize diseases knowledge, narrate therapeutic scheme, nursing method and matters needing attention, and introduce the attending doctor. Healthy manual may be made and distributed, or relevant films may be produced. Besides, the patients who have recovered may be invited to tell their personal experiences. Meanwhile, the patients' questions should be answered patiently during the propaganda and education period, and the education should be mainly conducted for the weak link to correct patients' wrong cognition of diseases and treatment. (2) psychological nursing: except disease torment, the strange environment, new interpersonal relationship, insufficient cognition degree for operative treatment will make patients generate certain negative mood, which will further form insufficient compliance. Thus, psychological nursing should be introduced. Then nursing staff should give ear to patients actively, carefully and patiently, know their emotional changes and make them feel they are valued through body language and smile so as to enhance the sense of trust. For those with insufficient cognition of treatment, the technology of the attending doctor and typical successful cases should be introduced to relieve their negative mood, except necessary health education. Communication is based on the understanding degree of nursing staff for patients' basic information, including living habit and preference so that targeted psychological intervention can be conducted. Before the surgery, it is required to guide and help patients to complete relaxation training and let them inhale to keep their muscle in the tension state. Then, nursing staff should let them expire and relax. This process should be repeated for 10 times every day until patients' mental state recovers to complex relaxation. Meanwhile, music may be used for auxiliary intervention.

\subsection{Observation indexes}

1) Visual analogue scale (VAS) [4] was used for both groups after receiving nursing for $2 \mathrm{w}$ and $4 \mathrm{w}$ to evaluate the pains. The total score is 10 . The higher score means severer pains.

2) The compliance of both groups in the perioperative period was investigated. Complete compliance means the patients actively cooperate in the treatment; partial compliance means the patients basically actively cooperate in the treatment, and few patients need other's reminding. Poor compliance means patients do not actively cooperate in the treatment. Total compliance rate $=$ complete compliance rate + partial complete compliance.

\subsection{Statistical method}

SPSS21.0 statistics software package was used for data processing. The enumeration data "rate" was tested with chi-square value. Measurement data "mean \pm standard deviation" was tested with independent sample. $\mathrm{P}<0.05$ means the differences have statistical significance.

\section{RESULTS}

\subsection{VAS score comparison of both groups in each time bucket}

Tab.1 VAS score comparison of both groups in each time bucket $\left({ }_{x}^{-} \pm s\right)$

\begin{tabular}{cccc}
\hline Group & No. & Nursing for $2 \mathrm{w}$ & Nursing for $4 \mathrm{w}$ \\
\hline Research group & 35 & $3.03 \pm 0.41$ & $1.74 \pm 0.38$ \\
Control group & 35 & $5.46 \pm 0.25$ & $3.49 \pm 0.41$ \\
$t$ & $/$ & 29.94 & 18.52 \\
$\mathrm{P}$ & $/$ & $<0.05$ & $<0.05$ \\
\hline
\end{tabular}


VAS scores of the research group after receiving nursing for $2 \mathrm{w}$ and $4 \mathrm{w}$ were significantly lower than that of control group, and the differences had statistical significance $(\mathrm{P}<0.05)$ (Tab.1).

\subsection{Compliance comparison of both groups}

Compliance rate of research group was significantly higher than that of control group, and the and the differences had statistical significance $(\mathrm{P}<0.05)$ (Tab.2).

Tab.2 Compliance comparison of both groups $(n, \%)$

\begin{tabular}{|c|c|c|c|c|c|}
\hline Group & No & $\begin{array}{c}\text { Complete } \\
\text { complianc } \\
\text { e }\end{array}$ & $\begin{array}{c}\text { Partial } \\
\text { complianc } \\
\text { e }\end{array}$ & $\begin{array}{c}\text { Poor } \\
\text { complianc } \\
\text { e }\end{array}$ & $\begin{array}{l}\text { Complian } \\
\text { ce rate }\end{array}$ \\
\hline $\begin{array}{l}\text { Researc } \\
\text { h group }\end{array}$ & 35 & 24 & 8 & 3 & 91.43 \\
\hline $\begin{array}{l}\text { Control } \\
\text { group }\end{array}$ & 35 & 11 & 14 & 10 & 71.43 \\
\hline$x_{2}$ & / & / & / & / & 11.94 \\
\hline $\mathrm{P}$ & 1 & 1 & 1 & I & $<0.05$ \\
\hline
\end{tabular}

\section{DISCUSSIONS}

For patients, the surgery belongs to a kind of serious psychological stress. Psychological fear and physiological trauma will directly influence patients' normal mental activities, thus resulting in the impacts on the recovery after the surgery. They even may directly decide the success or failure of the surgery $[5,6]$. Most patients have severe concerns before the surgery. Especially for selective operation patients with stable diseases state, the reasons for their concerns include non-understanding of the surgery, doubt of the surgery effect, selection of the doctor, fear of pains and other problems from the family, society and interpersonal relationship. A clinical survey shows, for selective operation patients, they have such phenomena as expressionless face, voice trembling and tachycardia. The typical examination indexes are reflected in elevation of blood pressure and heart rate acceleration. Such stress responses will bring about severe impacts on the surgery [7-9]. The gradual change of clinical medicinal concept further promotes the changes of nursing mode, i.e. from only focusing on operation cooperation mode to concerning the direct relationship between psychology and physiology. Finally, nursing content extends to the attention to patients' psychological changes in the whole perioperative period.

In recent years, "people-oriented” core nursing value has been widely applied clinically. Through coordinating and maintaining the relationship between doctors and patients, patients can gradually adapt to the strange environment and interpersonal relationship. Especially in the nursing period of patients with typical psychological problems, targeted psychological nursing intervention formulated by the professional doctors can effectively relieve patients' negative mood, eliminate their concerns and make sure they receive the medical content with positive attitude. Health education is of great significance in the whole nursing period. Health education aims to guide patients to have certain basic cognition of their diseases and treatment method through systematic, well-organized and planned propaganda and education activities, and correct their wrong concepts. Health education effectively relieves patients' physiological and psychological stress so that their cooperation degree and enthusiasm improve significantly. The research result shows that VAS scores and compliance of the research group in each time bucket after the operation are obviously superior to that of control group, which indicates that the addition of targeted health education and psychological nursing content in the conventional nursing indeed has the ideal effect. Some researchers report tha the nursing strategy of psychological nursing combined with health education for the patients with coronary heart disease in the operative treatment period contributes to improving patients' psychological state, enhancing their mastery of disease knowledge and further boosting clinical effect. [10-12] In this research, the evidence on improving patients' negative mood and enhancing knowledge mastery is not gained, so the feasibility of this idea cannot be judged. 
Thus, further research is required to verify it.

In conclusion, the application of health education combined with psychological nursing for the patients receiving cardiothoracic surgery contributes to relieving patients' pain score and improving their clinical compliance, so it deserves to be promoted and applied clinically.

\section{REFERENCES}

[1] Lien CY , Lin HR , Kuo IT , Chen ML Perceived uncertainty, social support and psychological adjustment in older patients with cancer being treated with surgery.Journal of clinical nursing 2009 Aug; 18 (16 ) :2311-9.

[2] Mitchell MA, patient-centred approach to day surgery nursing. Nurs Stand 2010 Jul 7-13 (44): 40-6. [3]Sun H, Liu H, Li J , Wang X, The Patterns of Graded Psychological Nursing Care for Patients after Cardiothoracic Surgeries.Iranian journal of public health 2017 Jul; 46 (7 ) :899-905.

[4] Short A, Gibb H, Fildes J, Holmes C.Exploring the role of music therapy in cardiac rehabilitation after cardiothoracic surgery: a qualitative study using the Bonny method of guided imagery and music.The Journal of cardiovascular nursing 2013 Nov-Dec 28 (6 ) :E74-81.

[5] Agren S, Frisman GH, Berg S, Svedjeholm R, Strömberg A .Addressing spouses' unique needs after cardiac surgery when recovery is complicated by heart failure.Heart \& lung : the journal of critical care 2009 Jul-Aug 38 (4 ) :284-91.

[6] varsson B, Larsson S, Johnsson P, Lührs C, Sjöberg T, From hope and expectation to unexpected death after cardiac surgery.Intensive \& critical care nursing 2008 Aug; 24 (4): 242-50.

[7] Richards SH, Anderson L, Jenkinson CE, Whalley B, Rees K, Davies P, Bennett P, Liu Z, West R, Thompson DR, Taylor RS. Psychological interventions for coronary heart disease: Cochrane systematic review and meta-analysis.Eur J Prev Cardiol. 2018 Feb;25(3) :247-259.

[8] Enç N, Öz Alkan H, Nursing care in elderly patients with cardiovascular disease,Turk Kardiyol Dern Ars. 2017 Sep; 45(Suppl 5) :120-123.

[9] Stewart RAH, Colquhoun DM, Persistent psychological distress and mortality in patients with stable coronary artery disease.Heart. 2017 Dec;103(23) :1860-1866.

[10] An K, Salyer J, Kao HF, Psychological strains, salivary biomarkers, and risks for coronary heart disease among hurricane survivors.Biol Res Nurs. 2015 May;17(3) :311-20.

[11] Lee DT, Choi KC, Chair SY, Yu DS, Lau ST, Psychological distress mediates the effects of socio-demographic and clinical characteristics on the physical health component of health-related quality of life in patients with coronary heart disease.Eur J Prev Cardiol. 2014 Jan; 21(1) :107-16.

[12] Park JH, Bae SH,A systematic review of psychological distress as a risk factor for recurrent cardiac events in patients with coronary artery disease.J Korean Acad Nurs. 2011 Oct; 41(5) :704-14 